\title{
Dynamics in COVID-19 Symptoms During Different Waves of the Pandemic Among Children Infected with SARS-CoV-2
}

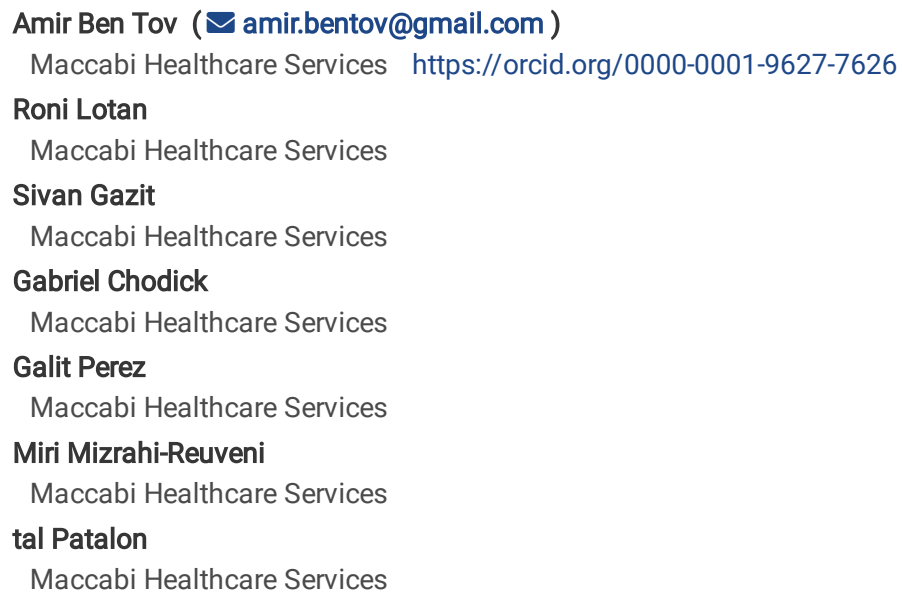

\section{Research Article}

Keywords: Coronavirus, Fever, Variants, Symptoms

Posted Date: February 2nd, 2022

DOI: https://doi.org/10.21203/rs.3.rs-1289584/v1

License: (c) (1) This work is licensed under a Creative Commons Attribution 4.0 International License. Read Full License 


\section{Abstract}

The aim of this real-life, big data population-based study was to evaluate differences in symptomatic presentation of children infected with Severe Acute Respiratory Syndrome Coronavirus-2 (SARS-CoV-2) between the third and fourth waves of the pandemic in Israel, dominated by the Alpha and Delta variants, respectively. Our cohort included all children and adolescents, members of the second-largest Health Maintenance Organisation in Israel that had positive real-time polymerase chain reaction (RT-PCR) test during the third and fourth waves of the pandemic (December 1, 2020 - April 30, 2021 , and June 1, 2021 October 10,2021, respectively). A total of 32,485 and 44,130 children and adolescents in the third and fourth waves were included in the final analysis. The rate of children with symptomatic disease among patients with documented SARS-CoV-2 infection was higher in the fourth wave compared to the third wave (49.9\% vs. $37.5 \%)$. The most commonly reported symptom and the only symptom that substantially differed between waves was fever, with $33 \%$ of SARSCoV-2 infected children in the fourth wave vs. $13.6 \%$ in the third wave. Preschool children had the lowest prevalence of febrile illness compared to other age groups.

Conclusion: Children and adolescents infected during the fourth wave of the pandemic in Israel, a Delta-dominant period, had a significantly higher rate of symptomatic febrile illness than the Alpha-dominant period. This phenomenon occurred across all age groups.

\section{What Is Known}

- There are differences in COVID-19 severity among adults and children during different waves of the pandemic.

- There is a paucity of data regarding symptomatic characteristics in children in large-scale cohorts aside from hospital settings.

\section{What is new:}

- In a time period dominated by the Delta variant, there were substantially more children with symptomatic disease and febrile illness compared to a period dominated by the alpha variant.

- Preschool children had the lowest rate of febrile illness among all age groups.

\section{Introduction}

The novel Severe Acute Respiratory Syndrome Coronavirus-2 (SARS-CoV-2) virus has caused over 250 million confirmed cases of Coronavirus Disease 2019 (COVID-19) globally and more than 5 million deaths as of November 2021.[1] Although children and adolescents are more susceptible to certain infectious diseases due to their immature immune system,[2] they had a less severe presentation of COVID-19 with significantly lower morbidity and mortality rates than adults. [3], $[4 ; 5]$

Pediatric hospitalization rates and outcomes were the focus of early research on COVID-19.[6] However, as most children are diagnosed and followed in the community, there is a paucity of data regarding symptoms in children with mild disease.

Children infected with COVID-19 present with a broad spectrum of non-specific symptoms[7], and a substantial amount of them (about 25\%) were considered asymptomatic[3], a presentation more prominent among younger children.[8]

Israel, like other countries, underwent a few surges during the COVID-19 pandemic since the initial occurrence in March 2020, with a probable different dominant variant at each period.[9] In the third and fourth waves, which account for most COVID-19 cases in Israel, the Alpha (B.1.1.7)[10] and the Delta (B.1.617.2)[11] were the most dominant variants. Few reports to date investigated the differences in the manifestations attributed to different variants in the pediatric population, and these have found that the variant might influence the clinical characteristics[12] and disease severity[13] of COVID-19 among children.

The present population-based study aimed to explore the clinical characteristics of SARS-CoV-2 infection reported in children and adolescents treated in ambulatory settings during different periods dominated by the Alpha and the Delta variants.

\section{Methods}

\section{Data Sources}

In this study, we used data originating from Maccabi Healthcare Services (MHS). MHS is the second largest Health Maintenance Organization (HMO) in Israel, accounting for $26.7 \%$ of the Israeli population. Membership in an HMO is compulsory in Israel under the National Health Insurance Law of 1995 , according to which all Israeli citizens must join one of the four official HMOs.

MHS has a centralized computerized database that contains extensive longitudinal data of a stable population of over 2.5 million individuals (of which $32 \%$ are children aged 0-16), with less than $1 \%$ annual turnover. The database contains demographic data, ambulatory and hospital diagnoses, anthropometric measurements, medication dispensed, and comprehensive laboratory data from a single central lab.

\section{Study design and population}

A retrospective cross sectional study was conducted. The study included children and adolescents under the age of 16 with SARS-CoV-2 infection confirmed by a positive real-time polymerase chain reaction (RT-PCR) test during the third and fourth waves of the pandemic for whom a symptoms questionnaire was 
available (see below). In Israel, PCR tests are readily available and offered for free, and the tests are obtained from nasopharyngeal swabs using nationally approved SARS-CoV-2 PCR testing kits.[14; 15]

Children were considered to have contracted SARS-CoV-2 in the third and the fourth wave if they tested positive between December 1, 2020 - April 30, 2021, and between June 1, 2021, and October 10, 2021 (end of analysis), respectively. As different variants characterized Israel's third and fourth waves, we did not include individuals infected during May 2021 to minimize the possible overlap between the variants. Patients with previously positive SARS-CoV-2 PCR tests and patients who received the COVID-19 vaccine were excluded.

\section{Data extraction and definition of the study variables Symptoms data}

According to the MHS workflow during the pandemic, upon a positive PCR test, a member's pediatrician or family physician was notified and obligated to initiate a phone call visit to assess the child's health status and whether the child has any symptoms. Correspondingly, in the electronic medical record, the physician filled in a structured symptom questionnaire (During the following 48 hours in most of the cases). If the patient presented with symptoms that were not included in the structured symptoms list, the physician could add them as free text. The physician remained in contact with the patient family, and in case of symptoms appearance, the questionnaire was updated. During data collection, our team tagged the free text information into structured binary categories and later assembled these categories into four groups as detailed below:

- Respiratory symptoms: cough, runny nose, sore throat, shortness of breath, ear pain and hoarseness

- Gastrointestinal symptoms: abdominal pain, vomiting, diarrhea, nausea, loss of appetite

- Neurology symptoms: disturbances of smell or taste, dizziness, headache

- General and other symptoms: fever, chills, fatigue, myalgia, conjunctivitis, ocular pain, chest pain, restlessness, weakness

\section{Age groups}

We categorized age into categorical variables using the following cutoffs: 0-1 years old (infants), 1-3 years old (toddlers), 3-6 years old (preschoolers), 6-12 years old (middle childhood), 12-16 years old (adolescents) to measure the magnitude of the difference in symptoms across the different age groups.

\section{Covariates}

Individual-level data of the study population included demographics, namely age, sex, and socioeconomic status (SES), measured on a scale from 1 (lowest) to 10 .

\section{Statistical analysis:}

We performed two separate analyses: the first included the whole cohort, both symptomatic and asymptomatic SARS-CoV-2 infected patients, the second comprised solely of the fraction of patients who had at least one symptom, defined as COVID-19 patients.

We summarized the patients' characteristics as mean \pm standard deviation for continuous data and as percentages for categorical data. We then compared the proportion of symptoms between the two waves. All outcomes were reported in the overall population and the sub-group by age. Linear regression models with quadratic, cubic, and linear terms were evaluated using the R2 value to determine the best fit functional form between age and prevalence of fever.

Due to the large population size, $P$-values were accompanied by standardized mean differences (the difference between the two groups' means divided by the pooled SD), in which a standardized mean difference greater than 0.2 was considered meaningful.

Statistical analyses were performed using SPSS statistical software version 27 (IBM).

\section{Ethics declaration}

The study was approved by the MHS (Maccabi Healthcare Services) Institutional Review Board (IRB).

\section{Results}

\section{Primary analysis: all infected individuals}

A total of 32,485 and 44,130 children were eligible for the analysis in the third and fourth waves, respectively. Figure 1 reveals a flowchart of the exclusion criteria. The mean age of the children with SARS-CoV-2 infection was 8.54 \pm 4.55 and $7.86 \pm 3.84$ years old, respectively (SMD=0.16). Gender proportion was similar between the two waves.

Demographics and rate of symptoms during both the third and fourth waves are presented in Table 1. We found a significant difference in the proportion of symptomatic children infected with SARS-CoV-2 between the third and the fourth waves with $37.5 \%$ and $49.9 \%$ of the children with SARS-CoV-2 infection had at least one reported symptom, respectively $(S M D=0.25)$. Fever was the most prevalent symptom in both waves and was 2.4 -fold more prevalent in the fourth wave than the third one $(S M D=0.47)$. The differences between the two waves' respiratory, gastrointestinal, and neurology symptoms were negligible. Hospitalization due to COVID-19 was rare and similar between the waves with $84(0.3 \%)$ and $96(0.2 \%)$ cases in the third and fourth waves, respectively. 
The proportion of symptoms by age is summarized in Table 2. Across all age groups, the proportion of general symptoms was more prevalent, ranging from 1.5-2.6 folded prevalence in the fourth wave compared to the third. Among the components of the general symptoms, fever was significantly more frequent (1.7 - 3.8 fold more prevalent) in the fourth wave than the third wave across all ages groups. (Figure 2).

During both waves, infants had the highest rate of febrile illness with a decrease in the rate until the age of 6 years (preschool children) and a steady increase in older children and adolescents, creating a J-like curve (Figure 2).

\section{Secondary analysis: only symptomatic individuals}

There were 12,198 and 22,007 children with at least one symptom in the third and fourth waves. Those children composed the COVID-19 patients' cohort. There was a significant difference in the proportions of general symptoms between the two waves reported in $54.6 \%$ and $75.7 \%$ (SMD $=0.45$ ) among COVID19 patients in the third and fourth wave, respectively. Fever was the most dominant symptom and the only component with a significant difference. In the third and fourth waves, it was reported in $36.1 \%$ and $66.1 \%(S M D=0.62)$ among COVID-19 patients, respectively. We also found a reduced frequency of respiratory symptoms in the fourth wave compared with the third ( $42.1 \%$ vs. $54.1 \%$ respectively, SMD $=0.24)$, which was more prominent in younger ages (up to 6 years). The proportion of gastrointestinal and neurology symptoms was similar between the two waves. The demographic, clinical characteristics, and difference in symptoms according to age groups is presented in Supplemental digital content (SDC) Table 3 and Table 4.

\section{Discussion}

Our study represents one of the largest pediatric cohorts to date describing symptoms of SARS-CoV-2 infected patients in ambulatory settings. The study describes changes in the rate of symptoms in different time frames where different variants were dominant. Specifically, it demonstrates that fever was the most common symptom with different rates in different age groups and significantly more dominant during the fourth wave in Israel that was dominated by the Delta variant. The rate of febrile illness during the fourth wave was $33 \%$ among SARS-CoV- 2 infected patients and $66 \%$ among COVID- 19 patients (symptomatic patients).

Differences in symptoms during differing pandemic periods were described in smaller cohorts. Chua et al. described the clinical characteristics and transmission patterns among children and youths with COVID-19 in Hong kong in 2020.[12] Their study found significant differences in the clinical presentations across the three waves of outbreaks (all before the Delta variant became dominant). The number of symptomatic children declined in the second and third waves compared to the first, but absolute numbers were low, and screening patterns might have changed over time. Somekh et al. described the increased spreading effectiveness of the Alpha variant in children compared to the first two waves of the pandemic in Israel; however, they did not report symptoms.[13]

The difference in febrile illness among different age groups is intriguing and enhances some of the assumptions of why children have less severe diseases than adults.[5] Preschool children had the lowest rate of febrile illness. Those children are post their toddler years where they were exposed to numerous viral illnesses that might enhance their innate and adapted immune response to coronaviruses in general.

Idyllo et al.[16] followed patients hospitalized with COVID-19 and looked for preexisting immunity for seasonal coronavirus. They found evidence for preexisting immunity that affects the humoral response to SARS-CoV-2. Anderson et al.[17] demonstrated that human serum samples before and after the onset of the COVID-19 pandemic with antibodies against common seasonal human coronaviruses are cross-reactive against SARS-CoV-2 but do not confer cross-protection against infection or hospitalization. In contrast, Guoma et al.[18] suggest that recent seasonal coronavirus infections potentially limit the duration of symptoms following SARS-CoV-2 infections through mechanisms that do not involve cross-reactive antibodies and postulate that cellular immune responses are involved.

This assumption is strengthened by our findings of the steady increase of febrile illness as children advance in age after the age of six years. This population of preschool children should be the focus of further assessments in order to look for the complex mechanism behind this phenomenon. Interestingly - Infants had the highest level of febrile response. This finding is in line with descriptions of higher morbidity in infants compared to older children.[19]

The proportion of fever and other symptoms in children was described in a few studies. The largest was an international network cohort described by DuarteSalles et al.[6] They described fever as the most common symptom ranging from 4.8 to $26.4 \%$ in different countries. This study took place before the emergence of the Delta variant. In another study from the united states, Parcha et al. described 12,306 COVID-19 patients. They have shown, similarly to our study, that fever was the most common symptom, although, in their study, there was a steady decline in the rate of fever from infants to adolescents. In another cohort from the beginning of the pandemic in the united states (data collection ended May 2020), Stokes et al.[20] described fever as the most common symptom in children. The rate was high (46\% percent in children aged 0-9 years and 35\% percent in 10-19 years). The rate of febrile illness was the rate among patients with reported symptoms, which was low among the whole cohort making it challenging to describe the actual rate of febrile illness among all SARS-CoV-2 infected children.

The strength of our study relates to the structure of the healthcare system in Israel, which offers extensive medical care to the general public at no cost, allowing excellent access to care.[21] Specifically, during the COVID-19 pandemic, PCR tests were offered at no cost for symptomatic patients and individuals exposed to verified SARS-CoV-2 patients,[22] allowing us to present the full spectrum of the disease in children from asymptomatic patients to patients with a variety of symptoms.

The limitation of the study includes the type of interaction between the physician and the patient's parents, which was based mainly on a telephone interview and not on office appointments. In addition, the questionnaire was filled once in most of the cases - post-positive PCR results, limiting the opportunity to

Page $4 / 11$ 
capture symptoms occurring later in the disease course. PCR results in the time period of the study did not undergo genomic sequencing; nevertheless, monitoring by the ministry of health showed that the third and fourth waves were dominated by the Alpha and Delta wave, respectively[10; 11]. This study

was limited to children because symptoms comparison in adults between waves could not be made during the same time-period as most Israeli population was already vaccinated during the fourth wave.

\section{Conclusion}

In conclusion, there was a significant difference in the rate of symptomatic febrile illness in children infected with SARS-CoV-2 between times where the Alpha and Delta variants were dominant. These findings imply that different variants have different virulence. Given the rapidly evolving pandemic, the clinical relevance of emerging variants is important to public health. Therefore, ongoing surveillance of symptoms in large cohorts is crucial to provide meaningful and accurate information to clinicians and policymakers.

\section{List Of Abbreviations}

Coronavirus Disease 2019 (COVID-19)

Health Maintenance Organization (HMO)

Severe Acute Respiratory Syndrome Coronavirus-2 (SARS-CoV-2)

\section{Declarations}

Funding: No funding interest to declare.

Conflicts of interest/Competing interests: All authors report no conflicts of interest

Availability of data and material: N/A

Code availability: N/A

Authors' contributions:

Acquisition of data: Amir Ben Tov, Roni Lotan, Sivan Gazit, Galit Perez

Analysis and interpretation of data: All authors

Drafting of the manuscript: Amir Ben Tov, Roni Lotan

Critical revision of the manuscript for important intellectual content: Sivan Gazit, Gabriel Chodic, Galit Perez, Miri Mizrahi-Reuveni, Tal Patalon.

Study supervision: Tal Patalon

All authors had full access to all of the data and approved the final version of this manuscript. All authors take responsibility for the integrity of the data and the accuracy of the data analysis.

Ethics approval The study was approved by the MHS (Maccabi Healthcare Services) Institutional Review Board (IRB).

Consent to participate: N/A

Consent for publication: all authors approved the latest version of the manuscript

\section{References}

1. Hopkins J (2020) COVID-19 Dashboard by the Center for Systems Science and Engineering (CSSE). Coronavirus Resource Center

2. Simon AK, Hollander GA, Mcmichael A (2015) Evolution of the immune system in humans from infancy to old age. Proceedings of the Royal Society B: Biological Sciences 282:20143085

3. Li B, Zhang S, Zhang R, Chen X, Wang Y, Zhu C (2020) Epidemiological and Clinical Characteristics of COVID-19 in Children: A Systematic Review and Meta-Analysis. Front Pediatr 8:591132

4. Bailey LC, Razzaghi H, Burrows EK, Bunnell HT, Camacho PEF, Christakis DA, Eckrich D, Kitzmiller M, Lin SM, Magnusen BC, Newland J, Pajor NM, Ranade D, Rao S, Sofela O, Zahner J, Bruno C, Forrest CB (2021) Assessment of 135794 Pediatric Patients Tested for Severe Acute Respiratory Syndrome Coronavirus 2 Across the United States. JAMA Pediatrics 175:176

5. Zimmermann P, Curtis N (2021) Why is COVID-19 less severe in children? A review of the proposed mechanisms underlying the age-related difference in severity of SARS-CoV-2 infections. Arch Dis Child 106:429-439

6. Duarte-Salles T, Vizcaya D, Pistillo A, Casajust P, Sena AG, Lai LYH, Prats-Uribe A et al (2021) Thirty-Day Outcomes of Children and Adolescents With COVID-19: An International Experience. Pediatrics 148:e2020042929

Page 5/11 
7. Parcha V, Booker KS, Kalra R, Kuranz S, Berra L, Arora G, Arora P (2021) A retrospective cohort study of 12,306 pediatric COVID-19 patients in the United States. Scientific Reports 11

8. Katayama Y, Zha L, Kitamura T, Hirayama A, Takeuchi T, Tanaka K, Komukai S, Shimazu T, Sobue T (2021) Characteristics and Outcomes of Pediatric COVID-19 Patients in Osaka, Japan. Int J Environ Res Public Health 18:5911

9. Muhsen K, Na'Aminh W, Lapidot Y, Goren S, Amir Y, Perlman S, Green MS, Chodick G, Cohen D (2021) A nationwide analysis of population group differences in the COVID-19 epidemic in Israel, February 2020-February 2021. The Lancet Regional Health - Europe 7:100130

10. Munitz A, Yechezkel M, Dickstein Y, Yamin D, Gerlic M (2021) BNT162b2 vaccination effectively prevents the rapid rise of SARS-CoV-2 variant B.1.1.7 in high-risk populations in Israel. Cell Reports Medicine 2:100264

11. Goldberg Y, Mandel M, Bar-On YM, Bodenheimer O, Freedman L, Haas EJ, Milo R, Alroy-Preis S, Ash N, Huppert A (2021) Waning Immunity after the BNT162b2 Vaccine in Israel. New England Journal of Medicine

12. Chua GT, Wong JSC, Lam I, Ho PPK, Chan WH, Yau FYS, Rosa Duque JS et al (2021) Clinical Characteristics and Transmission of COVID-19 in Children and Youths During 3 Waves of Outbreaks in Hong Kong. JAMA Network Open 4:e218824

13. Somekh I, Stein M, Karakis I, Simões EAF, Somekh E (2021) Characteristics of SARS-CoV-2 Infections in Israeli Children During the Circulation of Different SARS-CoV-2 Variants. JAMA Network Open 4:e2124343

14. Chodick G, Tene L, Rotem RS, Patalon T, Gazit S, Ben-Tov A, Weil C, Goldshtein I, Twig G, Cohen D, Muhsen K (2021) The Effectiveness of the Two-Dose BNT162b2 Vaccine: Analysis of Real-World Data. Clinical Infectious Diseases

15. Mizrahi B, Shilo S, Rossman H, Kalkstein N, Marcus K, Barer Y, Keshet A, Shamir-Stein NA, Shalev V, Zohar AE, Chodick G, Segal E (2020) Longitudinal symptom dynamics of COVID-19 infection. Nature Communications 11

16. Aydillo T, Rombauts A, Stadlbauer D, Aslam S, Abelenda-Alonso G, Escalera A, Amanat F, Jiang K, Krammer F, Carratala J, García-Sastre A (2021) Immunological imprinting of the antibody response in COVID-19 patients. Nature Communications 12

17. Anderson EM, Goodwin EC, Verma A, Arevalo CP, Bolton MJ, Weirick ME, Gouma S et al (2021) Seasonal human coronavirus antibodies are boosted upon SARS-CoV-2 infection but not associated with protection. Cell 184:1858-1864e1810

18. Gouma S, Weirick ME, Bolton MJ, Arevalo CP, Goodwin EC, Anderson EM, Mcallister CM, Christensen SR, Dunbar D, Fiore D, Brock A, Weaver J, Millar J, Derohannessian S, Unit TUCP, Frank I, Rader DJ, Wherry EJ, Hensley SE (2021) Health care worker seromonitoring reveals complex relationships between common coronavirus antibodies and COVID-19 symptom duration. JCI Insight 6

19. Dong Y, Mo X, Hu Y, Qi X, Jiang F, Jiang Z, Tong S (2020) Epidemiology of COVID-19 Among Children in China. Pediatrics 145:e20200702

20. Stokes EK, Zambrano LD, Anderson KN, Marder EP, Raz KM, Felix SEB, Tie Y, Fullerton KE (2020) Coronavirus disease 2019 case surveillance-United States, January 22-may 30, 2020. Morb Mortal Wkly Rep 69:759

21. Clarfield AM, Manor O, Nun GB, Shvarts S, Azzam ZS, Afek A, Basis F, Israeli A (2017) Health and health care in Israel: an introduction. The Lancet 389:2503-2513

22. Mizrahi B, Lotan R, Kalkstein N, Peretz A, Perez G, Ben-Tov A, Chodick G, Gazit S, Patalon T (2021) Correlation of SARS-CoV-2-breakthrough infections to time-from-vaccine. Nature Communications 12

\section{Tables}


Table 1

Demographic and symptoms proportion by wave in the overall cohort

\begin{tabular}{|c|c|c|c|}
\hline & 3rd Wave & 4th Wave & SMD \\
\hline Age ,mean (SD), years & $8.54 \pm 4.55$ & $7.86 \pm 3.84$ & 0.16 \\
\hline Gender,$\%$ male & 51.8 & 51.2 & 0.013 \\
\hline Socioeconomic status, median (IQR) & $5(4-7)$ & $6(4-7)$ & 0.282 \\
\hline \multicolumn{4}{|l|}{ Symptoms } \\
\hline Any symptom No.(\%) & $12198(37.5)$ & 22007 (49.9) & 0.25 \\
\hline General symptoms, n (\%) & $6671(20.5)$ & $16680(37.8)$ & 0.387 \\
\hline Fever & 4409 (13.6) & $14552(33.0)$ & 0.472 \\
\hline Weakness & $2426(7.5)$ & $3938(8.9)$ & 0.053 \\
\hline Myalgia & $1489(4.6)$ & $2259(5.1)$ & 0.025 \\
\hline Restlessness & $108(0.3)$ & $69(0.2)$ & 0.036 \\
\hline conjunctivitis & $46(0.1)$ & $155(0.4)$ & 0.042 \\
\hline Chest pain & $16(0.0)$ & $25(0.1)$ & 0.003 \\
\hline Ocular pain & $41(0.1)$ & $90(0.2)$ & 0.019 \\
\hline Fatigue & $60(0.2)$ & $96(0.2)$ & 0.007 \\
\hline Chills & $34(0.1)$ & $23(0.1)$ & 0.019 \\
\hline Neurology symptoms, n (\%) & $3377(10.4)$ & $5306(12.0)$ & 0.052 \\
\hline Headache & $2366(7.3)$ & $4095(9.3)$ & 0.072 \\
\hline Disturbances in smell and taste & $1152(3.5)$ & $1418(3.2)$ & 0.018 \\
\hline Dizziness & $56(0.2)$ & $68(0.2)$ & 0.005 \\
\hline Gastrointestinal symptoms, n (\%) & $1217(3.7)$ & $2120(4.8)$ & 0.052 \\
\hline Diarrhea & $698(2.1)$ & $962(2.2)$ & 0.002 \\
\hline Abdominal pain & $349(1.1)$ & $685(1.6)$ & 0.042 \\
\hline Vomiting & $121(0.4)$ & $437(1.0)$ & 0.075 \\
\hline Loss of appetite & $90(0.3)$ & $105(0.2)$ & 0.008 \\
\hline Nausea & $42(0.1)$ & $129(0.3)$ & 0.036 \\
\hline Respiratory symptoms, n (\%) & $6605(20.3)$ & $9269(21.0)$ & 0.017 \\
\hline Cough & $4499(13.8)$ & $6438(14.6)$ & 0.021 \\
\hline Runny nose & $1698(5.2)$ & $2589(5.9)$ & 0.028 \\
\hline Sore throat & $1106(3.4)$ & $1219(2.8)$ & 0.037 \\
\hline Breath shortness & $272(0.8)$ & $318(0.7)$ & 0.013 \\
\hline Hoarseness & $30(0.1)$ & $36(0.1)$ & 0.004 \\
\hline Earache & $35(0.1)$ & $46(0.1)$ & 0.001 \\
\hline Hospitalization & $84(0.3)$ & $96(0.2)$ & 0.04 \\
\hline
\end{tabular}

Table 1: Explanation and abbreviation: IQR (interquartile range), SD (standard deviation), Central nervous system (CNS). SMD (Standardized mean difference) is the difference between the groups' means divided by the pooled SD 
Table 2

Symptoms proportion stratified by wave and age group in the entire cohort

\begin{tabular}{|c|c|c|c|c|c|c|c|c|c|c|c|c|c|c|c|}
\hline & $0-1 y$ & & & $1-3 y$ & & & $3-6 y$ & & & $6-12 y$ & & & $>12 y$ & & \\
\hline Wave & 3 & 4 & SMD & 3 & 4 & SMD & 3 & 4 & SMD & 3 & 4 & SMD & 3 & 4 & SMD \\
\hline$n$ & 1696 & 1585 & & 3339 & 4102 & & 5339 & 8957 & & 12983 & 23346 & & 9128 & 6140 & \\
\hline $\begin{array}{l}\text { General and } \\
\text { other } \\
\text { symptoms, n } \\
(\%)\end{array}$ & $\begin{array}{l}557 \\
(32.8)\end{array}$ & $\begin{array}{l}784 \\
(49.5)\end{array}$ & 0.34 & $\begin{array}{l}607 \\
(18.2)\end{array}$ & $\begin{array}{l}1431 \\
(34.9)\end{array}$ & 0.38 & $\begin{array}{l}581 \\
(10.9)\end{array}$ & $\begin{array}{l}2595 \\
(29.0)\end{array}$ & 0.46 & $\begin{array}{l}2277 \\
(17.5)\end{array}$ & $\begin{array}{l}8954 \\
(38.4)\end{array}$ & 0.47 & $\begin{array}{l}2649 \\
(29.0)\end{array}$ & $\begin{array}{l}2916 \\
(47.5)\end{array}$ & 0.38 \\
\hline $\begin{array}{l}\text { Respiratory } \\
\text { symptoms, n } \\
(\%)\end{array}$ & $\begin{array}{l}589 \\
(34.7)\end{array}$ & $\begin{array}{l}553 \\
(34.9)\end{array}$ & $<0.01$ & $\begin{array}{l}867 \\
(26)\end{array}$ & $\begin{array}{l}1000 \\
(24.4)\end{array}$ & 0.03 & $\begin{array}{l}783 \\
(14.7)\end{array}$ & $\begin{array}{l}1424 \\
(15.9)\end{array}$ & 0.03 & $\begin{array}{c}1995 \\
(15.4)\end{array}$ & $\begin{array}{l}4562 \\
(19.5)\end{array}$ & 0.11 & $\begin{array}{l}2371 \\
(26)\end{array}$ & $\begin{array}{l}1730 \\
(28.2)\end{array}$ & 0.05 \\
\hline $\begin{array}{l}\text { Gastrointestinal } \\
\text { symptoms, } \mathrm{n} \\
(\%)\end{array}$ & $\begin{array}{l}144 \\
(8.5)\end{array}$ & $\begin{array}{l}130 \\
(8.2)\end{array}$ & 0.01 & $\begin{array}{l}205 \\
(6.1)\end{array}$ & $\begin{array}{l}263 \\
(6.4)\end{array}$ & 0.01 & $\begin{array}{l}167 \\
(3.1)\end{array}$ & $\begin{array}{l}367 \\
(4.1)\end{array}$ & 0.05 & $\begin{array}{l}429 \\
(3.3)\end{array}$ & $\begin{array}{l}1126 \\
(4.8)\end{array}$ & 0.07 & $\begin{array}{l}272 \\
(3.0)\end{array}$ & $\begin{array}{l}234 \\
(3.8)\end{array}$ & 0.04 \\
\hline $\begin{array}{l}\text { Neurology } \\
\text { symptoms, n } \\
(\%)\end{array}$ & $\begin{array}{l}3 \\
(0.2)\end{array}$ & $\begin{array}{l}4 \\
(0.3)\end{array}$ & 0.01 & $\begin{array}{l}14 \\
(0.4)\end{array}$ & $\begin{array}{l}32 \\
(0.8)\end{array}$ & 0.04 & $\begin{array}{l}102 \\
(1.9)\end{array}$ & $\begin{array}{l}353 \\
(3.9)\end{array}$ & 0.12 & $\begin{array}{c}1410 \\
(10.9)\end{array}$ & $\begin{array}{l}3481 \\
(14.9)\end{array}$ & 0.12 & $\begin{array}{l}1848 \\
(20.2)\end{array}$ & $\begin{array}{l}1436 \\
(23.4)\end{array}$ & 0.07 \\
\hline
\end{tabular}

Table 2: Explanation and abbreviation: SMD (Standardized mean difference) is the difference between the groups' means divided by the pooled SD. 
Table 3

Demographic and symptoms proportion by wave in symptomatic patients

\begin{tabular}{|c|c|c|c|}
\hline & 3rd Wave & 4th Wave & SMD \\
\hline No. of patients & 12,198 & 22,007 & \\
\hline Age ,mean (SD), years & $9.26 \pm 4.89$ & $8.29 \pm 4.00$ & 0.17 \\
\hline Gender ,\% male & 49.6 & 49.6 & $<0.01$ \\
\hline Socioeconomic status, median (IQR) & $5(4-7)$ & $6(4-7)$ & 0.317 \\
\hline General symptoms, n (\%) & $6671(54.6)$ & $16680(75.7)$ & 0.45 \\
\hline Fever & $4409(36.1)$ & $14552(66.1)$ & 0.62 \\
\hline Weakness & $2426(19.8)$ & $3938(17.8)$ & 0.05 \\
\hline Myalgia & $1424(11.6)$ & $2122(9.64)$ & 0.06 \\
\hline Restlessness & $108(0.88)$ & $69(0.31)$ & 0.07 \\
\hline Conjunctivitis & $46(0.37)$ & $155(0.70)$ & 0.04 \\
\hline Chest pain & $16(0.13)$ & $25(0.11)$ & 0.005 \\
\hline Ocular pain & $41(0.33)$ & $90(0.40)$ & 0.01 \\
\hline Fatigue & $60(0.49)$ & $96(0.43)$ & 0.008 \\
\hline Chills & $34(0.27)$ & $23(0.10)$ & 0.03 \\
\hline Neurology symptoms, $\mathrm{n}(\%)$ & $3377(27.6)$ & $5306(24.1)$ & 0.08 \\
\hline Headache & $2366(19.3)$ & 4095 (18.6) & 0.01 \\
\hline Disturbances in smell and taste & $1152(9.44)$ & $1418(6.44)$ & 0.11 \\
\hline Dizziness & $56(0.45)$ & $68(0.30)$ & 0.02 \\
\hline Gastrointestinal symptoms, n (\%) & $1217(9.97)$ & $2120(9.63)$ & 0.01 \\
\hline Diarrhea & $698(5.72)$ & $962(4.37)$ & 0.06 \\
\hline Abdominal pain & $349(2.86)$ & $685(3.11)$ & 0.01 \\
\hline Vomiting & $121(0.99)$ & $437(1.98)$ & 0.08 \\
\hline Loss of appetite & $90(0.73)$ & $105(0.47)$ & 0.03 \\
\hline Nausea & $42(0.34)$ & $129(0.58)$ & 0.03 \\
\hline Respiratory symptoms, n (\%) & $6605(54.1)$ & $9269(42.1)$ & 0.24 \\
\hline Cough & 4499 (36.8) & $6438(29.2)$ & 0.16 \\
\hline Runny nose & $1698(13.9)$ & $2589(11.7)$ & 0.06 \\
\hline Sore throat & $1106(9.06)$ & $1219(5.53)$ & 0.13 \\
\hline Breath shortness & $272(2.22)$ & $318(1.44)$ & 0.05 \\
\hline Hoarseness & $30(0.24)$ & $36(0.16)$ & 0.01 \\
\hline Earache & $35(0.28)$ & $46(0.20)$ & 0.01 \\
\hline
\end{tabular}

Table 1: Explanation and abbreviation: IQR (interquartile range), SD (standard deviation), SMD (Standardized mean difference) is the difference between the groups' means divided by the pooled SD 
Table 4

Symptoms proportion stratified by wave and age group in the symptomatic patients

\begin{tabular}{|c|c|c|c|c|c|c|c|c|c|c|c|c|c|c|c|}
\hline & $0-1 y$ & & & $1-3 y$ & & & $3-6 y$ & & & $6-12 y$ & & & $12-16$ & & \\
\hline Wave & 3 & 4 & & 3 & 4 & & 3 & 4 & & 3 & 4 & & 3 & 4 & \\
\hline$n$ & 897 & 999 & SMD & 1231 & 1908 & SMD & 1262 & 3457 & SMD & 4231 & 11816 & SMD & 4557 & 3827 & SMD \\
\hline $\begin{array}{l}\text { General and } \\
\text { other } \\
\text { symptoms, } \mathrm{n} \\
(\%)\end{array}$ & $\begin{array}{l}557 \\
(62.0)\end{array}$ & $\begin{array}{l}784 \\
(78.4)\end{array}$ & 0.36 & $\begin{array}{l}581 \\
(46.0)\end{array}$ & $\begin{array}{l}1431 \\
(75.0)\end{array}$ & 0.54 & $\begin{array}{l}581 \\
(46.0)\end{array}$ & $\begin{array}{l}2595 \\
(75.0)\end{array}$ & 0.62 & $\begin{array}{l}2277 \\
(53.8)\end{array}$ & $\begin{array}{l}8954 \\
(75.7)\end{array}$ & 0.47 & $\begin{array}{l}2649 \\
(57.8)\end{array}$ & $\begin{array}{l}2916 \\
(76.1)\end{array}$ & 0.39 \\
\hline $\begin{array}{l}\text { Respiratory } \\
\text { symptoms, n } \\
(\%)\end{array}$ & $\begin{array}{l}589 \\
(65.6)\end{array}$ & $\begin{array}{l}553 \\
(55.3)\end{array}$ & 0.21 & $\begin{array}{l}867 \\
(70.4)\end{array}$ & $\begin{array}{l}1000 \\
(52.4)\end{array}$ & 0.37 & $\begin{array}{l}783 \\
(62.0)\end{array}$ & $\begin{array}{l}2371 \\
(47.1)\end{array}$ & 0.42 & $\begin{array}{l}1995 \\
(47.1)\end{array}$ & $\begin{array}{l}4562 \\
(38.6)\end{array}$ & 0.17 & $\begin{array}{l}2371 \\
(51.8)\end{array}$ & $\begin{array}{l}1730 \\
(45.2)\end{array}$ & 0.13 \\
\hline $\begin{array}{l}\text { Gasrto } \\
\text { intestinal } \\
\text { symptoms, n } \\
(\%)\end{array}$ & $\begin{array}{l}144 \\
(16.0)\end{array}$ & $\begin{array}{l}130 \\
(13.0)\end{array}$ & 0.08 & $\begin{array}{l}205 \\
(16.6)\end{array}$ & $\begin{array}{l}263 \\
(13.7)\end{array}$ & 0.08 & $\begin{array}{l}167 \\
(13.2)\end{array}$ & $\begin{array}{l}367 \\
(10.6)\end{array}$ & 0.08 & $\begin{array}{l}429 \\
(10.1)\end{array}$ & $\begin{array}{l}1126 \\
(9.5)\end{array}$ & 0.02 & $\begin{array}{l}272 \\
(5.9)\end{array}$ & $\begin{array}{l}234 \\
(6.1)\end{array}$ & $<0.01$ \\
\hline $\begin{array}{l}\text { Neurology } \\
\text { symptoms, n } \\
(\%)\end{array}$ & $\begin{array}{l}3 \\
(0.3)\end{array}$ & $\begin{array}{l}4 \\
(0.4)\end{array}$ & 0.01 & $\begin{array}{l}14 \\
(1.1)\end{array}$ & $\begin{array}{l}32 \\
(1.6)\end{array}$ & 0.04 & $\begin{array}{l}102 \\
(8.0)\end{array}$ & $\begin{array}{l}353 \\
(10.2)\end{array}$ & 0.07 & $\begin{array}{l}1410 \\
(33.3)\end{array}$ & $\begin{array}{l}3481 \\
(29.4)\end{array}$ & 0.08 & $\begin{array}{l}1848 \\
(40.3)\end{array}$ & $\begin{array}{l}1436 \\
(37.5)\end{array}$ & 0.05 \\
\hline
\end{tabular}

Table 4: Explanation and abbreviation: SMD (Standardized mean difference) is the difference between the groups' means divided by the pooled SD.

\section{Figures}

\section{Figure 1.}

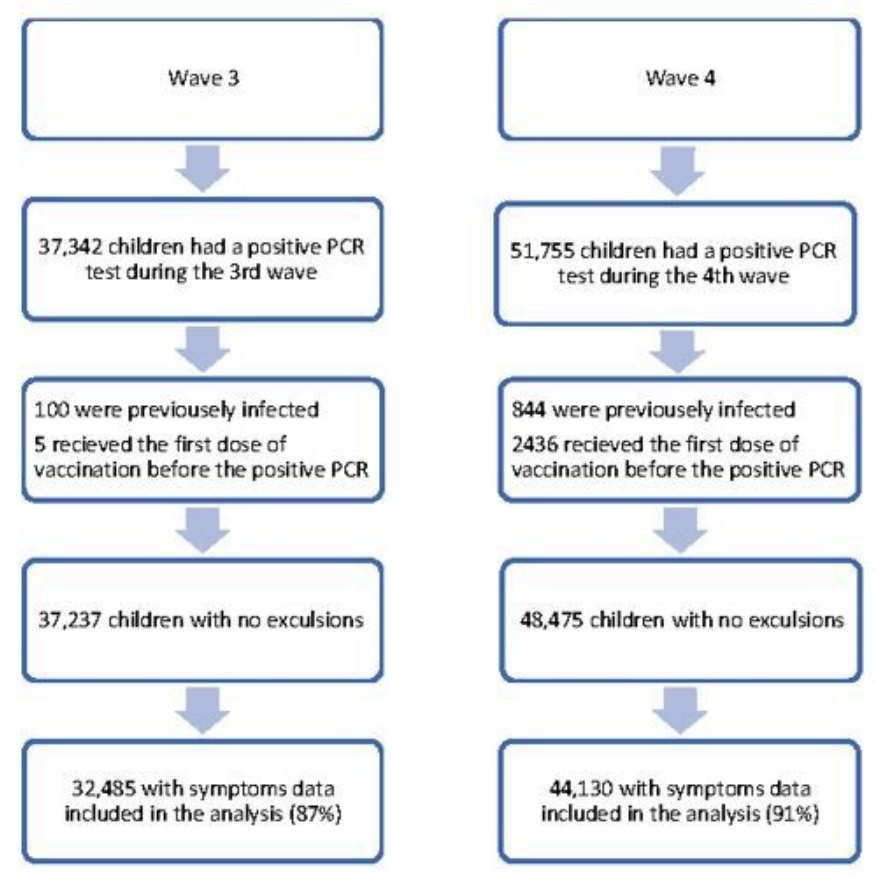

\section{Figure 1}

Flowchart of the children infected with SARS-CoV-2 Included in the study cohort.

Figure 1: explanation and abbreviation:

Polymerase chain reaction (PCR), period of wave 3: Dec $1^{\text {st }} 2020$ - April $30^{\text {th }} 2021$, period of wave 4: June $1^{\text {st }} 2021-0$ ctober $10^{\text {th }}$ (the end of analysis). 


\section{Figure 2.}

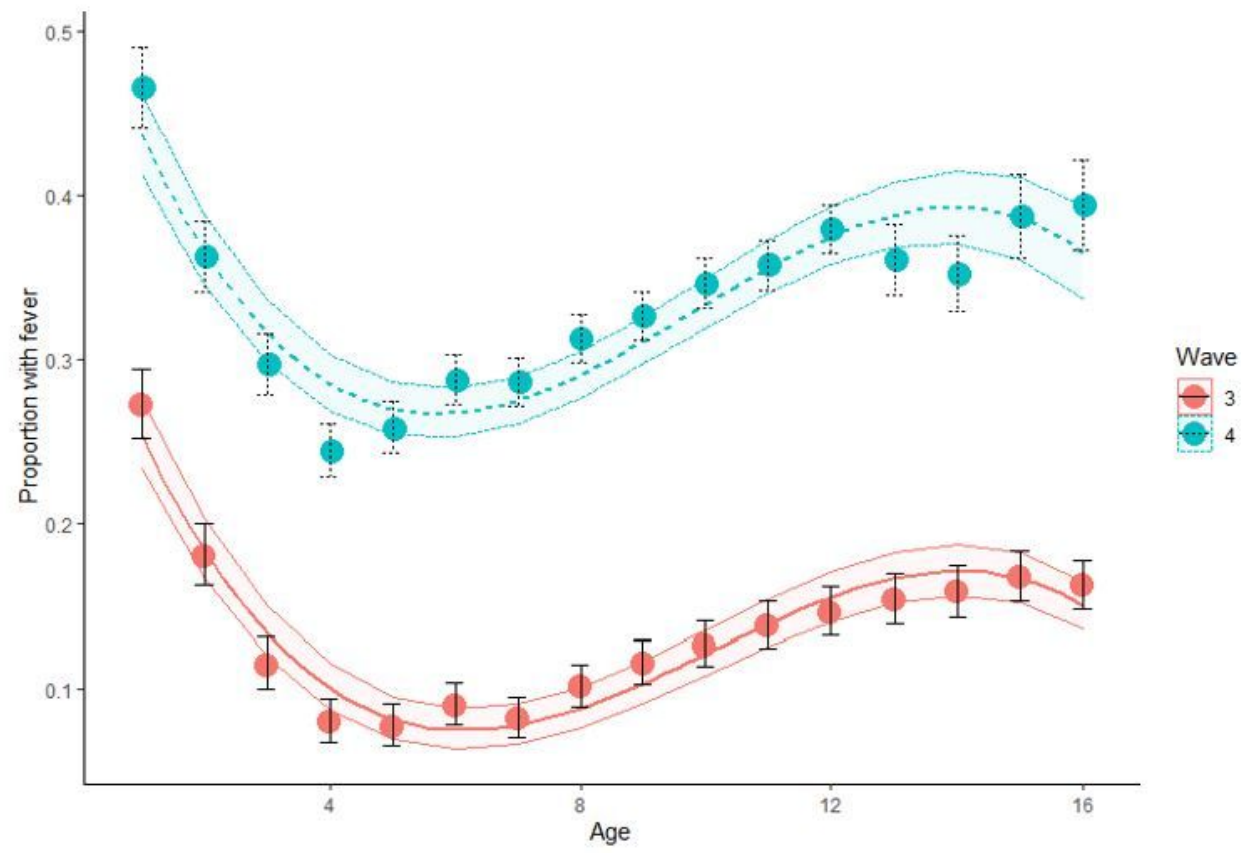

Figure 2

Rate of febrile illness by age in the third and fourth wave 